\title{
Upper Gastro-Intestinal Endoscopy in Pregnancy- Experience at a Tertiary Care Centre of North India
}

\author{
Vani Malhotra*, Parul Singh, Parveen Malhotra, Smiti Nanda, Meenakshi Chauhan and Vandana Bhuriya \\ Department of Gynecology \& Obstetrics and Medical Gastroenterology, PGIMS, India
}

Submission: September 07, 2017; Published: November 22, 2017

"Corresponding author: Vani Malhotra, Department of Gynaecology \& Obstetrics and Medical Gastroenterology, PGIMS, 128/19, Civil Hospital Road, Rohtak, Haryana, India, Email: drparveenmalhotra@yahoo.com

Abstract

Introduction: Gastrointestinal (GI) endoscopy has a definite role in the diagnosis and management of gastrointestinal disorder. Though its clinical efficacy and safety is well established in non pregnant patients but its safety has not been well studied in the pregnant woman. Due to its inherent risk to both mother and fetus it should be performed during pregnancy only when there is no other better way available to diagnose or treat the gastrointestinal disorder.

Methods: We conducted a retrospective analysis of all pregnant females who were subjected to upper GI endoscopy over five years (20102015) in Pandit Bhagwat Dayal Sharma, PGIMS, Rohtak with the aim of determining the various etiological factor responsible for subjecting a pregnant female female to upper GI endoscopy.

Result: A total of 35 patients were subjected to upper GI endoscopy over the period of 5 years (2010 to 2015) in our tertiary care center. Out of 35 women, 22 (62.8\%) had upper GI bleed, 11(31.4\%) had refractory vomiting and 2 (0.6\%) were suffering from dysphasia.

Conclusion: Upper GI endoscopy can be used both for diagnostic and therapeutic purposes. Though it is considered low risk procedure in pregnancy but should only be done for limited strong indications. Due to limited literature on safety profile it should be delayed till post partum if possible. It should always be a multidisciplinary approach. It should not be done by beginners.

\section{Introduction}

Gastrointestinal (GI) endoscopy has a definite role in the diagnosis and management of gastrointestinal disorder. Though its clinical efficacy and safety is well established in non pregnant patients but its safety has not been well studied in the pregnant woman. Due to its inherent risk to both mother and fetus it should be performed during pregnancy only when there is no other better way available to diagnose or treat the gastrointestinal disorder.

It should be only done for limited indications [1]:
a) Significant or continued GI bleed
b) Severe or refractory nausea and vomiting or abdominal pain
c) Dysphasia or odynophagia
d) Severe diarrhea with negative evaluation
e) Biliary pancreatitis

f) Symptomatic choledocholithiasis or cholangitis

g) Biliary or pancreatic ductal injury.

Endoscopic risks for the pregnant woman can be:

a) Precipitated aspiration due to abdominal distension

b) Hypotension due to inferior vena cava compression

c) Uterine trauma due to anatomical modification.

Potential risks to fetus are hypoxia due to oversedation; teratogenicity as a result of sedative and anesthetic medication used and preterm labor [2]. The risks vary with the duration of pregnancy. If possible should be postponed till delivery and if not then should abide by certain principles:

a) Regardless of gestational age it should include a preoperative obstetrician consultation 
b) It should have a strong indication

c) It should be deferred till second trimester

d) Lowest effective dose of sedative medication should be used that too category B drugs whenever possible

e) Minimize the procedure time

f) It should be done in left lateral position

g) Fetal heart sound should be confirmed before and after the procedure

h) It is contraindicated in placental abruption, imminent delivery, ruptured membranes and uncontrolled eclampsia.

There should always be pre-procedure evaluation and stabilization of patients. A medical history focused on the GI history, obstetrical status, comorbidities, and anesthesiology risks is obtained before scheduling endoscopy during pregnancy. It should always be a combined decision of an obstetrician, gastroenterologist and anesthetist. Patients should be medically stabilized before endoscopy, with an endpoint of relatively stable vital signs and relatively normal levels of key serum electrolytes and blood counts. In particular, patients with GI bleeding should receive volume resuscitation and should have severe coagulopathy corrected by transfusion of fresh frozen plasma or platelets as necessary [3]. It is important for successful endoscopic hemostasis.

Patients with active upper GI hemorrhage may undergo nasogastric tube lavage or administration of prokinetic agents, to clear the endoscopic field, potentially shorten procedure time, and decrease intraprocedural aspiration risks [4]. Patients are kept nothing per orally (npo) for several hours before endoscopy to avoid intraprocedural aspiration of gastric contents [3]. As very limited indications are recommended to perform upper GI endoscopy in pregnant women, our study aimed to study various etiological factors responsible for subjecting a pregnant female for upper GI endoscopy in a tertiary care center of North India.

\section{Methods}

We conducted a retrospective analysis of all pregnant females who were subjected to upper GI endoscopy over five years (20102015) in Pandit BhagwatDayal Sharma, PGIMS, Rohtak with the aim of determining the various etiological factor responsible for subjecting a pregnant female female to upper GI endoscopy.

\section{Results}

A total of 35 patients were subjected to upper GI endoscopy over the period of 5 years (2010 to 2015) in our tertiary care center. Out of 35 women, 22(62.8\%) had upper GI bleed, 11(31.4\%) had refractory vomiting and $2(0.6 \%)$ were suffering from dysphasia (Table 1). After the women subjected to upper GI endoscopy the findings were analyzed. As demonstrated in Table 2 out of 22 women with GI bleed, 10 (45.4\%) were reported to have erosive gastritis, 2(0.9\%) had Mallory-Weiss tear, 3(1.3\%) had esophagitis, $2(0.9 \%)$ had duodenitis, $(0.4 \%)$ had variceal bleed and no abnormality was found in rest $4(1.8 \%)$ cases.

Table 1: Distribution of subjects according to their presenting complains.

\begin{tabular}{|c|c|c|}
\hline Presenting Complains & No. of Pregnant Women & Frequency(N) \\
\hline Upper GI bleed & 22 & $62.80 \%$ \\
\hline Refractory vomiting & 11 & $31.40 \%$ \\
\hline Dysphasia & 2 & $0.60 \%$ \\
\hline
\end{tabular}

Table 2: Distribution of etiology found in endoscopy of 22 pregnant women with upper GI bleed.

\begin{tabular}{|c|c|c|}
\hline Cause & No. of Women & Frequency (N) \\
\hline Erosive gastritis & 10 & $45.40 \%$ \\
\hline Mallory-Weiss tear & 2 & $0.90 \%$ \\
\hline Esophagitis & 3 & $1.30 \%$ \\
\hline Duodenitis & 2 & $0.90 \%$ \\
\hline Variceal bleed & 1 & $0.40 \%$ \\
\hline No cause & 4 & $1.80 \%$ \\
\hline
\end{tabular}

Mallory Weiss tear were managed by Argon plasma coagulation. Variceal bleed were managed by Endoscopic variceal ligation and rest of the patients were managed by proton pump inhibitors. Out of 11 patients who presented with refractory vomiting 4 (36.6\%) were reported to have hiatus hernia and 7 (63.6\%) patients didn't have any abnormality in endoscopy. One of the 2 patients who had endoscopy for dysphagia had Plummer Winson syndrome. Oesophageal web was broken with the help of endoscope.

\section{Discussion and conclusion}

Upper GI endoscopy can be used both for diagnostic and therapeutic purposes. Though it is considered low risk procedure in pregnancy but should only be done for limited strong indications. Due to limited literature on safety profile it should be delayed till post partum if possible. It should always be a multidisciplinary approach. It should not be done by beginners.

Savas N has concluded in his study that all GI endoscopic procedures in pregnant patients should be performed in hospitals by expert endoscopists and an obstetrician should be informed about all endoscopic procedures. It may be performed safely in pregnant patients when there are strong indications. To minimize fetal risks from drugs during endoscopy, category D drugs should be avoided, drug use should be minimized and an anesthesiologist should attend at endoscopy [5]. Friedel D et al. [3] also have the same opinion in their study.

The safety of gastrointestinal endoscopy during the pregnancy was evaluated by Cappell et al. [6] who performed esophago-gastroduodenoscopies on a lot of 83 pregnant women and concluded on the fact that the procedure is safe and does not induce birth or congenital malformations. A survey performed by 300 specialist 
gastroenterologists doctors, which included information regarding 73 digestive superior endoscopies and 13 colonoscopies performed during the pregnancy, did not succeed to report any significant complication for those pregnancies [7]. So, if upper GI endoscopy is done rationally by expert gastroenterologist with adherence to proper principles and for strong indications in association with expert obstetrician and anesthetist then optimal maternal and fetal outcome will be obtained.

\section{References}

1. Amandeep KS, Ben-Menachem T, Chandrasekhara V, Chathadi K, Anton Decker G, et al. (2012) ASGE: Guidelines for endoscopy in pregnant and lactating women. Gastrointestinal Endoscopy 76(1): 18-24.

2. Mitrut P, Docea AO, Calina CD, Streba L (2013) Endoscopy in pregnancy. INTECH, pp. 349-362.

DOI: 10.19080/ARGH.2017.08.555729
3. Friedel D, Stavropoulos S, Iqbal S, Cappell MS (2014) Gastrointestinal endoscopy in the pregnant woman. World J Gastrointest Endosc 6(5): 156-167.

4. Laine L, Jensen DM (2012) Management of patients with ulcer bleeding. Am J Gastroenterol 107(3): 345-360.

5. Savas N (2014) Gastrointestinal endoscopy in pregnancy. World J Gastroenterol 20(41): 15241-15252.

6. Cappell MS, Colon VJ, Sidhom OA (1996) A study of eight medical centers of the safety and clinical efficacy of esophagogastroduodenoscopy in 83 pregnant females with follow-up of fetal outcome with comparison control groups. Am J Gastroenterol 91(2): 348-354.

7. Frank B (1994) Endoscopy in pregnancy. In: Karlstadt RG, Surawicz CM, Croitoru R (Eds.), Gastrointestinal Disorders During Pregnancy. American College of Gastroenterology, US, pp. 24-29.

\section{Your next submission with Juniper Publishers will reach you the below assets}

- Quality Editorial service

- Swift Peer Review

- Reprints availability

- E-prints Service

- Manuscript Podcast for convenient understanding

- Global attainment for your research

- Manuscript accessibility in different formats

( Pdf, E-pub, Full Text, Audio)

- Unceasing customer service

Track the below URL for one-step submission https://juniperpublishers.com/online-submission.php 